\title{
Psychosocial Correlates of Sexual Harassment among Female Undergraduates in Ekiti State
}

\author{
Mokuolu, Bolade Olubunmi \\ Department of Psychology and Behavioural Studies \\ Faculty of the Social Sciences \\ Ekiti State University, Ado Ekiti, Nigeria
}

\begin{abstract}
The contemporary complications of sexual harassment among females is at its alarming rate as each day unfolds, and as long as there are social interactions there will always be attractions, which may either lead to warm attention or harassment. This may be associated with fashion which is determined by people of different personality, the kind of natural body shape or self-structured body shape and self-esteem of individuals. This study examined the Psycho-social factors predicting sexual harassment among female undergraduates. Sexual harassment questionnaire, index of self-esteem and Big five personality inventory were employed for the study, though only two dimensions of personality (Extraversion and neuroticism) were considered. Six body shapes were also presented to the respondents to choose which of them actually describe their look; this was used to find out if body shapes could make an individual to be prone to sexual harassment. One hundred and four female undergraduates of Ekiti State University were randomly selected through cluster sampling. Three hypotheses were tested using Analysis of Variance. Result showed a significant main effect of self-esteem and also significant interaction effect of extraversion and self-esteem on sexual harassment. Place of abode has a significant effect on whether there will be sexual harassment or not, so also is family type. Respondents living with guardian reported the highest level of harassment, while those living with both parents reported the lowest level; those from polygamous family are significantly higher than those from monogamous family. Lastly Body shape has no significant effect on sexual harassment.
\end{abstract}

Keywords: Sexual harassment, Personality, Self-esteem, Family type, Place of abode, Body shapes

\section{INTRODUCTION}

Human beings are social beings made up of male and female. As long as there are interactions there will always be attraction from the opposite sex, sometimes the attraction is reciprocated and sometimes it is not. When sexual attractions are mutual and reciprocated, it is regarded as a socially acceptable sexual life. Meanwhile there are situations when one party is not in agreement and the other want to have his way at all cost it becomes anti-social behaviour which often leads to psychological problems with the victims of such harassment. Although because this issue seems to have come to stay among the youths especially the undergraduates, it has almost become an accepted norm. Aluede [1] tried to define and explain sexual harassment as unsolicited, unwelcomed, and unreciprocated sexual overture from a person to elicit unwanted sexual relations from another person. It can be expressed in both verbal and non-verbal ways, most of the time from someone who is in a position to take advantage of the other. This may occur in any setting which may include instructors in schools, boss in a place of work, guardians at home, relatives and even siblings that are older or has an influence over the other person's life. 
The issues of sexual harassment have been reported globally as well as in Nigeria. A study by Glaser and Thorpe [2] carried out in the US reported higher prevalence of sexual harassment and unethical intimacy between postgraduate students and their supervisors than the undergraduates due to frequent face- to-face interaction when seeking advice on their research studies. This has also been affirmed in the Nigerian education institutions where male lecturers take advantage of their position to sexually harass the female undergraduates as reported by Imonike, Aluede and Idogho [3].

Sexual harassment which is a form of harassment includes such behaviors and comments that can negatively affect not only the victim but his/her work environment and quality of life. There is always a possibility that a woman might experience some type of harassment whether she is at home, in the office, or in street [4]. Sexual harassment is a type of abuse which includes behaviors such as unwanted comments, suggestive looks or jokes, verbal abuse, terrorization or threats, obnoxious pictures, offensive messages and email [5]. Such types of unwanted behaviors cause feelings of discomfort for people, who must be very much careful about differentiating between their professional responsibilities and their protection. Dannenbaum and Jayaram [6] described sexual harassment as a male claim of control over women which badly affects the basic right of women to freely move in public spaces and get financial independence. Though sexual harassment is presented as a miner and harmless act, it causes serious consequences for the victim, such as emotional stress and physical disturbance which can lead to illness and eventually hospitalization. The psychological consequences of emotional stress can include anxiety, uneasiness, and depression, lack of self-esteem and lack of confidence. Similarly, consequences of physical trauma include insomnia, headaches, nausea and ulcers. The harassed women may experience illness, humiliation, anger, loss of selfconfidence and psychological distress $[7,8,9,10]$. In some cases, it may lead to resignation [11]. Sexual harassment at workplace increases anxiety and affects performance which ultimately negatively impacts on self-esteem and satisfaction with job $[12,13]$.

Personality being individuals' differences constitutes enduring personal characteristics that are revealed in an emotional and cognitive pattern of behavior in a variety of situation [14]. According to Costa and McCrae [15], the big five personality traits represent five broad domains of personality that are often used to describe human personality, these include: Extraversion, Conscientiousness, Agreeableness, Neuroticism and openness to experience. Neuroticism domains, including trait depression and trait anxiety, have been shown to relate to various forms of internalizing dysfunction, including major depression associated with sexual harassment [16].

Rosenberg $[17,18]$ who defines the self-esteem as "the evaluation which the individual makes and customarily maintains towards himself or herself: it expresses an attitude of approval or disapproval towards oneself". Self-esteem reflects a person's overall subjective emotional evaluation of his or her own worth. It is a judgment of oneself as well as an attitude toward the self. Self-esteem encompasses beliefs (for example, "I am competent", "I am worthy") and emotions such as triumph, despair, pride, and shame [19]. Smith and Mackie [20] defined it by saying "The self-concept is what we think about the self; self-esteem, is the positive or negative evaluations of the self, as, in how we feel about it. Self-esteem can apply specifically to a particular dimension (for example, "I believe I am a good writer and feel happy about that") or a global extent (for example, "I believe I am a bad person, and feel bad about myself in general") [21]. Psychologists usually regard self-esteem as an enduring personality characteristic ("trait" self-esteem), though normal, short-term variations ("state" self- esteem) also exist. Synonyms or near- synonyms of self-esteem include: self- worth, self-regard, selfrespect, and self-integrity [40]. 
Different negative life experiences such as continuous criticism, physical and verbal abuse and comments of being unattractive or unworthy can decrease self- esteem [22]. Low self-esteem negatively affects moods, behaviors and thoughts; it affects decision making and selfexpressing ability of a person. A person with low self-esteem relies on approval from others and compromises his values $([24,25]$.

Similar to the literature on maltreatment, sexual victimization of females from childhood has been linked to deficits in self-processes and development. Psychosocial theory posits that sexual abuse disrupts cognitive components of the self, leading to a proliferation of negative self- evaluations and negative core beliefs, including a sense of inferiority and low self-efficacy $[26,27,28]$. Many studies have demonstrated an association between sexual abuse and low self-esteem in children [29,30], even when some other forms of victimization were controlled [31]. Moreover, research shows that both children and adults with a history of sexual abuse are more likely to blame themselves for negative events and demonstrate lower self-efficacy than non-abused individuals $[32,33]$. Thus, it is possible that the lower levels of mastery, selfesteem, and depressive symptoms typically reported by adolescent girls [34] may, in part, be a function of stronger associations between victimization exposure and these outcomes among girls.

Human body shape is a complex phenomenon with sophisticated detail and function. The general body or figure of a person is defined mainly by the molding of skeletal structures, as well as the distribution of muscles and fat [35] McCormack [35] classified female body shapes into four categories, which are: Rectangular, Inverted triangle, Spoon and Hourglass. The waist measurement of rectangular shape is less than 9 inches smaller than the hips and bust measurement. Body fat is distributed predominantly in the abdomen, buttocks, chest, and face. This overall fat distribution creates the typical ruler (straight) shape. Inverted triangle shaped women have broader shoulders compared with their (narrower) hips. The legs and thighs tend to be slim, while the abdomen and chest look larger compared with the rest of the body. Fat is mainly distributed in the abdomen, chest and face. While in the case of Spoon, the hip measurement is greater than the bust measurement. The distribution of fat varies, with fat tending to deposit first in the buttocks, hips, and thighs. As body fat percentage increases, an increasing proportion of body fat is distributed around the waist and upper abdomen. The women of this body type tend to have a relatively larger rear, thicker thighs, and a smaller bosom. Hourglass or X shape (triangles opposing, facing in hourglass figure) the hips and bust are almost of equal size with a narrow waist. Body fat distribution tends to be around both the upper body and lower body. This body type enlarges the arms, chest, hips, and rear before other parts, such as the waist and upper abdomen.

\section{THE OBJECTIVES OF THE STUDY}

To determine the source, and trend of sexual harassment among female students in higher institutions in Nigeria and the psychological factors as well as the social factors that may make an individual to be prone to sexual harassment. The study specifically examined some personality variables which are neuroticism and extraversion and also self-esteem as they relate with sexual harassment. Body shape and social factors such as family type, place of abode, marital status of parents were also examine to see if they affect the rate at which an individual will be prone to sexual harassment.

\section{METHODS}

This study made use of two hundred and four female undergraduates in Ekiti state university, which cut across all the faculties. To achieve this, cluster sampling was used as copies of the 
questionnaire were distributed to students in their hostels where students from different faculties could be reached easily.

Questionnaire on sexual harassment was used. This includes items that describe the different ways by which harassment can take place, the frequency and by whom the harassment occurs. Self-esteem scale by Rosenberg [17] was employed to measure the level of self-esteem perceived by the respondents; while big five personality inventory by Rammstedt [23] was used to measure personality. Only two dimensions of personality were considered for this work, these are Extraversion and Neuroticism. Lastly, six body shapes were presented to the respondents to choose which of them actually describe their look. This was used to find out if body shape could make an individual to be prone to sexual harassment.

\section{RESULTS}

Table 1: Descriptive table showing the mean and standard deviation of scores on sexual harassment

\begin{tabular}{|c|c|c|c|c|}
\hline \multicolumn{2}{|l|}{ Variables } & $\mathrm{N}$ & Mean & S D \\
\hline \multirow[t]{2}{*}{ Neuroticism } & High & 139 & 3.50 & 3.83 \\
\hline & Low & 111 & 3.50 & 3.54 \\
\hline \multirow{2}{*}{ Extraversion } & High & 139 & 3.71 & 3.75 \\
\hline & Low & 111 & 2.74 & 3.58 \\
\hline \multirow[t]{2}{*}{ Self-esteem } & High & 111 & 4.05 & 3.89 \\
\hline & Low & 139 & 2.66 & 3.43 \\
\hline \multirow[t]{5}{*}{ Place of abode } & Both parents & 160 & 2.96 & 3.36 \\
\hline & Father & 4 & 3.50 & 4.04 \\
\hline & Mother & 36 & 4.97 & 3.86 \\
\hline & Guardian & 7 & 6.29 & 4.49 \\
\hline & Close relation & 10 & 6.00 & 4.52 \\
\hline \multirow[t]{2}{*}{ Family type } & Monogamous & 147 & 2.99 & 3.41 \\
\hline & Polygamous & 68 & 4.84 & 3.90 \\
\hline \multicolumn{2}{|l|}{ Total } & 250 & 3.28 & 3.70 \\
\hline
\end{tabular}

Table 2: 2x2x2 Anova Table Showing the Effect of Extraversion, Neuroticism and Self-Esteem on Sexual Harassment.

\begin{tabular}{|l|c|c|c|c|}
\hline Source & Sum of square & Df & Mean square & F \\
\hline Extraversion & 39.64 & 1 & 39.64 & 3.06 \\
\hline Neuroticism & 8.13 & 1 & 8.13 & .63 \\
\hline Self-esteem & 105.60 & 1 & 105.60 & $8.16^{* *}$ \\
\hline Extraversion* Neuroticism & 17.10 & 1 & 17.10 & 1.32 \\
\hline Extraversion* Self-esteem & 47.83 & 1 & 47.83 & $3.69^{*}$ \\
\hline Neuroticism* Self-esteem & 28.51 & 1 & 28.51 & 2.20 \\
\hline Extraversion* SE*Neurotic & 19.13 & 1 & 19.13 & 1.48 \\
\hline Error & 3129.73 & 242 & 12.93 & \\
\hline Total & 3414.40 & 249 & & \\
\hline
\end{tabular}

* significant at .05; ${ }^{* *}$ significant at .01

The result in Table above shows that, there is a significant main effect of self-esteem and also significant interaction effect of extraversion and self-esteem on sexual harassment.

Table 3: 2x4 ANOVA showing the effect of family type and place of abode on sexual harassment

\begin{tabular}{|l|c|c|c|c|}
\hline Source & Sum of squares & Df & Mean square & F \\
\hline Place of abode & 189.06 & 4 & 47.26 & $4.09^{* *}$ \\
\hline Family type & 119.66 & 1 & 119.66 & $5.19^{* *}$ \\
\hline Abode \& family type & 131.85 & 4 & 32.96 & $2.86^{*}$ \\
\hline Error & 2376.72 & 207 & 11.53 & \\
\hline Total & 2909.92 & 216 & & \\
\hline
\end{tabular}


* significant at $.05 ; \quad * *$ significant at .01

Result from table 3 showed that, place of abode has a significant effect on whether there will be sexual harassment or not, so also is family type. Observation of the mean from table 1 showed that Respondents living with guardian reported a higher level of harassment (mean $=6.29$ ); Those living with both parents reported the lowest level (mean $=2.96$ ); those from polygamous family are significantly higher (mean $=4.84)$ than those from monogamous family (mean $=2.99)$.

Table 4: Showing One way ANOVA table showing the influence of Body shape on sexual harassment

\begin{tabular}{|l|c|c|c|c|}
\hline Body shape & $\mathrm{N}$ & Mean & Std Deviation & $\mathrm{F}(5,207)$ \\
\hline Hourglass & 28 & 3.04 & 3.30 & 3.69 \\
\cline { 1 - 4 } Inverted triangle & 47 & 3.29 & 3.97 & \multirow{2}{*}{1.38} \\
\cline { 1 - 4 } Rectangle & 26 & 2.62 & 3.80 & \\
\hline Triangle & 63 & 4.36 & 4.52 & \\
\hline Diamond & 19 & 3.79 & 3.64 & \\
\hline Oval & 24 & 3.33 & & \\
\hline
\end{tabular}

Result in table 4 showed that, Body shape has no significant effect on sexual harassment.

\section{DISCUSSION}

The hypothesis which states that, there will be a significant effect of extraversion, neuroticism and self-esteem on sexual harassment was confirmed. Result with $2 \times 2 \times 2$ ANOVA shows that, there is a significant main effect of self-esteem whereby female undergraduates that are high on self-esteem recorded high mean of 4.05 on sexual harassment, while those with low selfesteem recorded mean of 2.66; and also a significant interaction effect of extraversion and selfesteem on sexual harassment. Self-esteem is conceived as a self-evaluation of self-worth or belief. Female undergraduates have proficient self-esteem in diverse areas like: sports, academics, music or arts, which could attract the attention of men under the disguise of fans to sexually harass or take an advantage of them. The result from this study is contrary to the work of Heather, David \& Richard [36] which indicated that sexual victimization independently reduced self- esteem, and also the work of Najma, Sadia, Numaira, \& Mohsin [37], who reported that sexual harassment was the significant predictor of low self-esteem. Although many studies have demonstrated an association between sexual abuse and low self-esteem in children [29, 30], but this study looks at sexual harassment among female undergraduates, where those who are high on self-esteem easily make themselves noticeable to others in every gathering, they are those who are willing to show their talents as well as their asset to others, therefore, there is high propensity that, females who have high self-esteem would wear dresses that will accentuate their body shapes, sizes and assets, which could attract the undue attention of sexual harassment from the opposite sex.

When extraversion is added to self-esteem, then there is also a tendency of females to be sexually harassed by males, because esteemed and sociable females have the tendencies to take risk, engage in social activities, they are gregarious, outgoing and friendly, they often club and party, people who are outgoing are more likely to be sexually harassed either boldly due to their high level of tolerance and when under the intoxicating influence of alcohol or surreptitiously sexually harassed by men under the disguise of crowded behavior.

Neuroticism does not have effect on sexual harassment in this study, this could be because neurotic females are too reserved, moody, private, anxious, and are more prone to negative emotions, these properties discountenance their attention and attraction of others that could sexually attract them. 
The other hypothesis states that, there will be a significant effect of family type and place of abode on sexual harassment. Result with $2 \times 4$ ANOVA revealed that, place of abode has a significant influence on whether there will be sexual harassment or not, so also is family type. Respondents living with guardian reported highest level of harassment (Mean=6.29) while those living with both parents reported the lowest level (mean $=2.96)$; those from polygamous family (Mean=4.84) are significantly higher than those from monogamous family(Mean=2.99). People who live in a polygamous family are more prone to sexual harassment than monogamies because, polygamous family is associated with too large family size, due to large family size, there is tendency for congestion of space, and lack of privacy or personal space among the children, this could lead to children disregarding and disrespecting themselves and this might ensued the feelings of sexual attraction that could in turn lead to sexual harassment among the children. Also, in polygamous setting, responsibilities of children are often laid on each mother in the family, since the father may not have adequate vigour to care for his children's emotional needs, attachment needs, belongingness, and family cohesion. If mothers are not financially and materially proficient also to take a very good care of their children's needs, such children could search for help in places where others might take easy advantage of them, due to the carelessness of the parents and experienced poverty. Unlike the monogamous family who are brief and concise enough to be cared for and to properly define the relationship that exist among them.

Females who live with guardians who are not related are likely to be sexually molested and harassed by the guardians or other people around them who may take advantage of them, they do this as a game of reward for their previous generous acts and their magnanimity towards the girl and as a factor for more benevolence. Females are also more likely to surrender themselves to sexual harassment from guardian in a way to sustain the help and benefits they receive. Those who live with relatives also reported high level of sexual harassment (Mean=6.00) unlike children who lives with their biological parents. It could therefore be said that upbringing has a great impact on exposure to sexual harassment.

The hypothesis that, body shape will have a significant effect on sexual harassment was not confirmed. The result as analysed with One Way ANOVA showed that, body shape did not significantly influence sexual harassment. Females have different body shapes (Hourglass, Triangle, Inverted triangle, Rectangle and Oval) any of these body shapes could be attractive to men at any point in time and depending on diverse preferences of men. The report from this study indicates that, none of these shapes automatically predict sexual harassment, it could be deduced then that, what provokes sexual harassment goes beyond the body shape. This is in contrary to the work of Lord [39] who reported a positive correlation between sexual harassment and body shapes. The appearance and carriage of the body might make ladies to become easily noticeable to the opposite sex, and too inviting enough, which may make them to be prone to sexual harassment. In general, women who reported negative feelings about being harassed tend to report feeling unhappy about aspects of their appearance.

\section{CONCLUSION}

This study assessed self-esteem, personality (extraversion and neuroticism), family types, place of abode and body shapes as psychosocial factors that could influence sexual harassment among female undergraduates in Ekiti State University. It could be deduced from these findings that, self-esteem is a significant factor in sexual harassment and an interaction of self-esteem and extraversion has significant impact on sexual harassment while neuroticism has no significant influence on sexual harassment. Family size and place of abode both have a significant influence on sexual harassment, revealing a significant increase in sexual harassment among ladies from polygamous family and those living with guardians or relations. 
Body shape according to this study is not a factor in sexual harassment. Therefore, it seems justifiable to conclude that, self-esteem, extraversion, family type and place of abode are correlates of sexual harassment among female undergraduates in Ekiti State University.

\section{RECOMMENDATIONS}

Based on this study, it was observed that females are vulnerable to sexual harassment not because of their shapes but might be their appearance and carriage of the body, it could therefore be said that modest dresses attract decent men while indecent attires attract bad men. Ladies should not in the name of fashion go to the extreme of showing their nakedness. A further study on appearance could be done in order to ascertain the social factors that are responsible for sexual harassment among female undergraduates, and the study could be extended to men, to find out the actual factors of attraction to them. Also, study could also be carried out on the relationship between exhibitionism and sexual harassment

It was observed that nurturing ones' child by guardian is an opportunity for luring the child to sexual harassment by the guardian. This research recommends that, proper and adequate care and affection of children can be best handled by both parents, as single parenthood and polygamous setting do not guarantee the best emotional nurturance for children.

This research also recommends to academic institution, a structured mechanism and counselling centers that encourage students to report any case of sexual misconducts of lecturers or students without having the fear of being victimized, as well as organizing training on the consequences of sexual harassment for both students and lecturers in the academic setting.

This research recommends to upcoming researchers who may be willing to work on predictors of sexual harassment, to check on any of these associating factors: Depression, anxiety, shock, denial, aggression, fear, frustration, irritability, insecurity, feelings of betrayal, confusion, feelings of being powerless, Shame, self-consciousness, low self-esteem, guilt, self-blame, isolation.

\section{References}

Aluede, 0.0. (2000). Sexual harassment of women employees in a Nigerian university: Implications for counselors. Guidance \& Counselling, 15(2), 27-32.

Glazer, R.D. \& Thorpe, J.S. (1986). Unethical intimacy: A survey of sexual contact and advances between psychology educators and female graduate student. American psychologist, 41, (1), 43-51.

Imonikhe, J. Aluede, O. \& Idogho, P. (2012). A survey of Teachers and Students' perception of Sexual harassment in tertiary institutions of Edo State. Nigeria Journal of Asian Social Science, 8 (1): 268-273

Ali, F. (2010). Sexual harassment in Pakistan: An invisible crime. SEPLAA News. 2010. Retrieved From: http://www.seplaafoundation.org/index.php/ 2011/01/ sexual harassment - in pakistan-an- invisible-crime.

Madison, J. \& Minichiello, V. (2001). Sexual harassment in healthcare: Classification of harassers and rationalization of sex-based harassment behavior. Journal of Nursing Administration, 31(11), 534 - 543.

Dannenbaum, T., \& Jayaram, K.. (2005).Combating sexual harassment at the work place: A handbook for woe, employers ad NGO's. Mumbai: India Centre for Humans Rights and Law.

Gabor, G. (2006). Sexual harassment at the workplace: Converging ideologies. Journal for the Study of Religions and Ideologies, 3(14), 102-111.

Hitlan, R. T., Pryor, J. B., Hesson-McInnis, M. S., \& Olson, M. (2009). Antecedents of gender harassment: An analysis of person and situation factors. Sex Roles, 61(11-12), 794-807.

Holcomb, W. R., \& Holcomb, M. G. (2008). A victim typology of sexual harassment. Psychological Reports, 103(3), 819-826. 
Langhout, R. D., Bergman, M. E., \& Cortina, L. M. (2005). Sexual harassment severity: Assessing situational and personal determinants and outcomes. Journal of Applied Social Psychology, 35(5), 975-1007.

Kath, L. M., Swody, C. A., Magley, V. J., Bunk, J. A., \& Gallus, J. A. (2009). Cross-level, three-way interactions among work-group climate, gender, and frequency of harassment on morale and withdrawal outcomes of sexual harassment. Journal of Occupational and Organizational Psychology, 82(1), 159-182.

Morgan, J. F., \& Porter, S. (1999). Sexual harassment of psychiatric trainees: experiences and attitudes. Postgraduate Medical Journal, 75(885), 410-413.

Romito, P., Ballard, T., \& Maton, N. (2004). Sexual harassment among female personnel in an Italian hospital Frequency and correlates. Violence against Women, 10(4), 386-417.

Mischel, W., Shoda, Y., \& Smith, R.E. (2004). Introduction to personality toward an integration. New York: John Wiley \& Sons.

Costa, P. \& McCrae, R. (1992). Revised NEO Personality Inventory (NEO-PI-R) and NEO Five-Factor Inventory (NEO-FFI) manual. Odessa, FL: Psychological Assessment Resources.

Settles, R.F., Cyders, M., \& Smith, G.T. (2010). Longitudinal validation of the acquired preparedness model of drinking risk. Psychology of Addictive Behaviors, 24, 198-208.

Rosenberg, M. (1965). Society and the adolescent self-image. New Jersey: Princeton University Press.

Rosenberg, M. (1986). Conceiving the self. Melbourne, FL: Academic Press.

Hewitt, John P. (2009). Oxford Handbook of Positive Psychology. Oxford University Press. pp. 217-224.

Smith, E. R.; Mackie, D. M. (2007). Social Psychology (Third ed.). Hove: Psychology Press. ISBN 978-1-84169-4085.

Orth U., Robbins R.W. (2014). "The development of self-esteem". Current Directions in Psychological Science 23 (5): 381-387.

Alexander, J. S. (2007). Seven day self-esteem booster. London: Hachette Children's Books.

Rammstedt, B. (2007). The big five personality inventory. European Journal of Psychological Assessment, 23(3), 193-201. Doi:10.1027/1015-5759.23.3.193

Coleman, J. (2010). The nature of adolescence (4th ed). London: Routledge. 178-189.

Patchin, J. W., \& Hinduja, S. (2010). Cyber-bullying and self-esteem. Journal of School Health, 80, 614 - 621.

Finkelhor, D. \& Browne, A. (1985). The traumatic impact of child sexual abuse: A conceptualization. American Journal of Orthop- sychiatry. 55, 530-541.

Harter, S. (1999). The construction of the self. New York: Guilford Press.

Putnam, F. W. (1990). Disturbances of "self" in victims of childhood sexual abuse. In R. Kluft (Ed.), Incest-related syndromes of adult psychopathology (pp. 113-131). Washington, DC: American Psychiatric Press.

Feiring, C., Taska, L., \& Lewis, M. (2002). Adjustment following sexual abuse discovery: The role of shame and attributional style. Developmental Psychology, 38, 79-92.

Stern, A. E., Lynch, D. L., Oates, R. K., \& O’Toole, B. I. (1995). Self -esteem, depression, behavior and family functioning in sexually abused children. Journal of Child Psychology \& Psychiatry and Allied Discipline, 36, $1077-$ 1089.

Bolger, K. E., \&, K. E., Patterson, C. J., \& Kupersmidt, J. B. (1998). Peer relationships and self-esteem among children who have been maltreated. Child Development, 69, 1171-1197.

Mannarino, A. P., Cohen, J. A., \& Berman, S. R. (1994). The Children's Attributions and Perceptions Scale: A new measure of sexual abuse-related factors. Journal of Clinical Child Psychology, 23, 204-211.

Paunovic, N. (1998). Cognitive factors in the maintenance of PTSD. Scandinavian Journal of Behaviour Therapy, 27, 167-178.

Rosenfield, S. (1999). Splitting the difference: Gender, the self, and mental health. In C. S. Aneshensel \& J. C. Phelan (Eds.), Hand- book of the sociology of mental health (pp. 209-224). New York: Kluwer Academic.

McCormack, H. (2005). "The shape of things to wear: Scientists identify how women's figures have changed in 50 years". The Independent. UK. How female body shapes have changed over time. 
Heather A. David, F., Richard, O. (2010). The Effects of Adolescent Victimization on Self-Concept and Depressive Symptoms. Child Maltreatment Volume 15 (1)76-90.

Najma, M., Sadia, M., Numaira, Q., Mohsin, A. (2014). Sexual Harassment as Predictor of Low Self Esteem and Job Satisfaction among In-Training Nurses. Journal of Social Sciences, Winter Vol. 8, No.2, 107-116. University of Sargodha.

Lord, T.T. (2009). The relationship of gender-based public harassment to body image, self-esteem and avoidance behaviour. Indiana University of Pennsylvania.

The American Heritage Dictionary of the English Language (2000) Defined "self-esteem; self-respect" in: Fourth Edition. Online at http://www.bartleby.com/61/58/ S0245800.html. Retrieved 15 November 2007. 